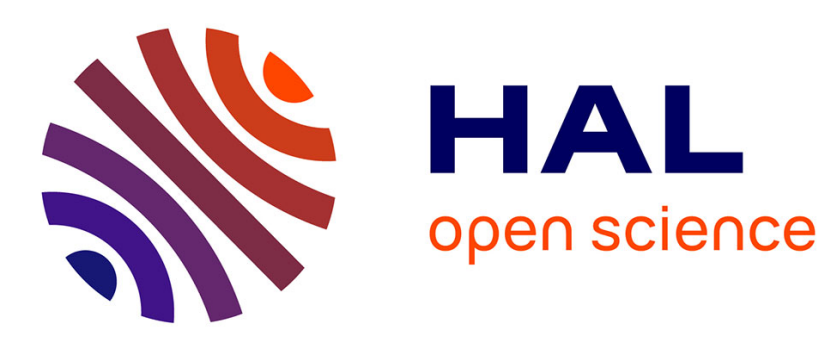

\title{
Dynamical Model of Residual Magnetism for Synchronous Reluctance Machine Control
}

Laurent Schuller, Jean-Yves Gauthier, Romain Delpoux, Xavier Brun

\section{To cite this version:}

Laurent Schuller, Jean-Yves Gauthier, Romain Delpoux, Xavier Brun. Dynamical Model of Residual Magnetism for Synchronous Reluctance Machine Control. IEEE Transactions on Industrial Electronics, 2021, 10.1109/TIE.2021.3127050 . hal-03255256

\section{HAL Id: hal-03255256 https://hal.science/hal-03255256}

Submitted on 9 Jun 2021

HAL is a multi-disciplinary open access archive for the deposit and dissemination of scientific research documents, whether they are published or not. The documents may come from teaching and research institutions in France or abroad, or from public or private research centers.
L'archive ouverte pluridisciplinaire HAL, est destinée au dépôt et à la diffusion de documents scientifiques de niveau recherche, publiés ou non, émanant des établissements d'enseignement et de recherche français ou étrangers, des laboratoires publics ou privés. 


\title{
Dynamical Model of Residual Magnetism for Synchronous Reluctance Machine Control
}

\author{
Laurent Schuller, Jean-Yves Gauthier, Romain Delpoux and Xavier Brun
}

\begin{abstract}
The present paper proposes an effective model for the control of synchronous reluctance machines. This model, called the ReMa Model, takes into account not only residual magnetism within the rotor of a synchronous reluctance machine, but also that within the stator. Electromotive forces generated by the ReMa Model were composed of two frequencies and exhibited similar shapes as those measured in experiments. Resultant equations in a three-phase $(a, b, c)$ frame and in a Park reference frame $(d, q)$ were revealed and divergences from commonly used models could be underlined. Experimental tests were carried out to prove the effectiveness of the ReMa Model which was also compared to a classical counterpart in the case where a synchronous reluctance generator was connected to a three-phase diode rectifier.
\end{abstract}

Index Terms-Back Electromotive Forces, Dynamical Model, Residual Magnetism, Synchronous Reluctance Machines

\section{INTRODUCTION}

Electrification is one way to reduce pollution and global warming by using electrical machines as motors or power generators. In 2011 electrical machines were responsible for between $43 \%$ and $46 \%$ of the total global electricity consumption according to [1] and out of this, medium power motors $(0.75 \mathrm{~kW}$ to $375 \mathrm{~kW})$ made up $68 \%$. This was mainly because of the use of Induction Machines (IM) which have relatively low efficiency. Among other efficient three-phase electrical motors, permanent magnet synchronous motors (PMSM) are nowadays widely used in numerous variable speed applications such as electric traction [2]. However, they have a main drawback: the presence of permanent magnets mostly made up of rare-earth elements [3] raises several ecological and economical issues. These matters force constructors to develop less magnets or even magnet-free motors such as synchronous reluctance (SynREL) motors [4] [5]. SynREL machines constitute a former technology when it comes to electrical actuators [6]. Because of phase switching issues and machine design, SynREL machines only became a serious competitor in the electrical machine market very recently.

Manuscript received Month $\mathrm{xx}, 2 \mathrm{xxx}$; revised Month $\mathrm{xx}$, xxxx; accepted Month $x, x x x x$. This work was supported in part by the $x x x$ Department of xxx under Grant (sponsor and financial support acknowledgment goes here).

Laurent Schuller, Jean-Yves Gauthier, Romain Delpoux and Xavier Brun are with the Univ Lyon, INSA Lyon, Universite Claude Bernard Lyon 1, Ecole Centrale de Lyon, CNRS, Ampère, UMR5005, 69621 Villeurbanne, France
These past decades, technological advances in power electronic and computer science have made SynREL machines more effective and novel designs are continuously developed to improve them [7]. Consequently, they now tend to compete with PMSMs after challenging traditional IMs [8] in different industrial applications [9] [10] [11] thanks to an enhanced efficiency and lower weight [12].

The literature has paid much attention to magnetic saturation [13] [14] and iron losses [15] [16] [17] for SynREL machines. Moreover, residual magnetic flux has been mentioned in self excitation phenomenon studies in generator applications. The latter is well known for IM [18] [19] and has been carried out for SynREL generators [20] [21]. In [22], the authors revealed the particular shape of back electromotive forces (EMF) produced by the residual magnetic flux without giving a clear explanation. Nonetheless, it has been demonstrated that the amplitude of this voltage is a critical criterium to ensure a self-excited start for both Induction [18] and SynREL generators [23] [24]. Yet, to the best of our knowledge, no paper presents a residual magnetic flux model. Such model could be used for system analysis and control law design.

This article aims to provide an effective dynamical model of the residual magnetic flux in SynREL machines. This model is available for control purposes, especially for applications at low voltage and high-speeds, such as generator voltage build-up. In such cases, residual magnetism has a major effect and for this reason, a precise model that includes residual magnetism is required.

The present paper is structured as follows: the problem statement is exposed in section II; section III contains the proposed models, in particular, models that take into account residual magnetism within the rotor and the stator; section IV transposes previous models into the Park reference frame; section V confronts simulations with experimental measurements; and section VI tests the model in simulation and compares the outcome with experimental results in a case study where the SynREL generator is connected to a threephase diode rectifier. The experimental measurements were performed for the SynREL generator. Finally; section VII presents conclusions and future work.

\section{Problem statement}

In general, three-phase electrical machine equations can be expressed by applying Kirchhoff's voltage law [25] as (1) :

$$
\frac{d L\left(\theta_{e}\right) i_{a b c}}{d t}=v_{a b c}-R_{s} i_{a b c}-e_{a b c},
$$


where $i_{a b c}=\left(\begin{array}{lll}i_{a} & i_{b} & i_{c}\end{array}\right)^{\top}$ is the vector of stator currents, $v_{a b c}=\left(\begin{array}{lll}v_{a} & v_{b} & v_{c}\end{array}\right)^{\top}$ is the vector of stator voltages, $e_{a b c}=$ $\left(\begin{array}{lll}e_{a} & e_{b} & e_{c}\end{array}\right)^{\top}$ is the vector of back EMF on each phase of the machine, $\theta_{e}$ is the electrical position of the rotor, $R_{s}$ is the resistor per phase and $L\left(\theta_{e}\right)$ is the inductance matrix that is defined more precisely in (2) and (3) ${ }^{1}$.

$$
L\left(\theta_{e}\right)=\left(\begin{array}{ccc}
L_{a} & M_{a b} & M_{c a} \\
M_{a b} & L_{b} & M_{b c} \\
M_{c a} & M_{b c} & L_{c}
\end{array}\right)
$$

with :

$$
\left\{\begin{array}{l}
L_{a}=L_{0}+L_{2} \cos \left(2 \theta_{e}\right) \\
L_{b}=L_{0}+L_{2} \cos \left(2 \theta_{e}+\frac{2 \pi}{3}\right) \\
L_{c}=L_{0}+L_{2} \cos \left(2 \theta_{e}-\frac{2 \pi}{3}\right) \\
M_{a b}=M_{0}+M_{2} \cos \left(2 \theta_{e}-\frac{2 \pi}{3}\right) \\
M_{b c}=M_{0}+M_{2} \cos \left(2 \theta_{e}\right) \\
M_{c a}=M_{0}+M_{2} \cos \left(2 \theta_{e}+\frac{2 \pi}{3}\right),
\end{array}\right.
$$

Here, $L_{0}, M_{0}$ and $L_{2}, M_{2}$ are respectively average values and amplitudes of phase inductances and mutual inductances. Iron losses have been neglected in the following developments. The expression of the produced torque is deduced from a power balance :

$$
\begin{aligned}
& P_{\text {meca }}=P_{\text {elec }}-P_{\text {Joule }}-P_{\text {storage }}, \\
& \Gamma_{e m} \Omega_{m}=v_{a b c}^{\top} i_{a b c}-R_{s} i_{a b c}^{\top} i_{a b c}-L\left(\theta_{e}\right) \frac{d i_{a b c}}{d t}{ }^{\top} i_{a b c}
\end{aligned}
$$

where $P_{\text {meca }}$ is the mechanical power, $P_{\text {elec }}$ the electrical power, $P_{\text {Joule }}$ the Joule losses, $P_{\text {storage }}$ the power stored in the inductances of the machine, $\Gamma_{e m}$ the torque generated by the machine and $\Omega_{m}$ the mechanical speed of the machine.

From (4) and (1), equation (5) gives the expression of the generated torque [27].

$$
\Gamma_{e m}=n_{p p}\left[\frac{\partial L\left(\theta_{e}\right)}{\partial \theta_{e}} i_{a b c}\right]^{\top} i_{a b c}+n_{p p} \frac{e_{a b c}^{\top} i_{a b c}}{\omega_{e}}
$$

where $n_{p p}$ is the number of pole pairs of the machine. The electrical position and speed are linked to their mechanical counterparts by the number of pole pairs: $\theta_{e}=n_{p p} \theta_{m}$ and $\omega_{e}=n_{p p} \Omega_{m}$.

Fig. 1 shows a SynREL machine with two pole pairs $\left(n_{p p}=2\right)$. The dark areas represent the iron while white parts are made of non-magnetic material such as air. The different annotations are introduced later in this paper.

In such machines, the variations of inductances are mainly responsible for the torque generation. Indeed, back EMF are generally neglected [25] because of the absence of magnets within the rotor, whether $e_{a b c}=0$. However, as for most electrical instruments, SynREL machines are mainly made of ferromagnetic materials. The hysteresis propriety of such materials leads to a small magnetic excitation after being subjected to an intense magnetic field. This results in back EMF not being zero. In this context, the present article deals with the theoretical development of the expression of back EMF and the experiments illustrate these results.

Remark 1. In this work, back EMF denote voltages produced when no current flows through the stator windings. Sometimes

${ }^{1}$ In theory $M_{0}=-\frac{1}{2} L_{0}$ and $L_{2}=M_{2}$ [26]

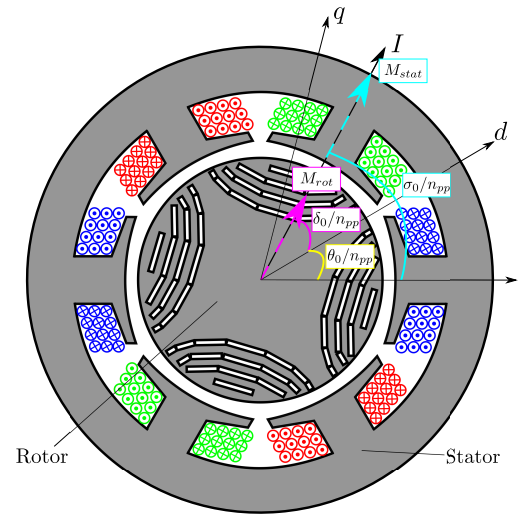

Fig. 1. Schematic cross-section of a SynREL machine with two pole pairs and phase windings (A: blue, B: red, C: green)

this term is employed to denominate the voltages generated by the reluctance variations. Depending on currents in each phase, they are not strictly back EMF from our point of view.

\section{Proposed ReMa model in AN $(a, b, c)$ Reference FRAME}

\section{A. Introduction to residual magnetism of the rotor}

To take into account the hysteresis property of a ferromagnetic material, studies have shown that the rotor is likely to be magnetized [22] [23]. Here we consider that it can be magnetized in any direction. This gives rise to a constant magnetization $m_{\text {rot }}$ in a direction defined by the angle $\delta_{0}$ (see Fig. 1) rotating with the rotor. From the perspective of the rotor, the reluctance is almost constant with the rotor position, thus $m_{\text {rot }}$ produces a positive constant flux denoted $\Phi_{\text {rot }}$. The back EMF produced by residual magnetism within the rotor are for each phase expressed as (6):

$$
\left\{\begin{array}{l}
e_{a, r o t}=-\Phi_{r o t} \omega_{e} \sin \left(\theta_{e}+\delta_{0}\right), \\
e_{b, r o t}=-\Phi_{r o t} \omega_{e} \sin \left(\theta_{e}+\delta_{0}-2 \pi / 3\right), \\
e_{c, r o t}=-\Phi_{r o t} \omega_{e} \sin \left(\theta_{e}+\delta_{0}+2 \pi / 3\right) .
\end{array}\right.
$$

Fig. 2 represents the normalized back EMF produced by residual magnetism within the rotor of a SynREL machine.

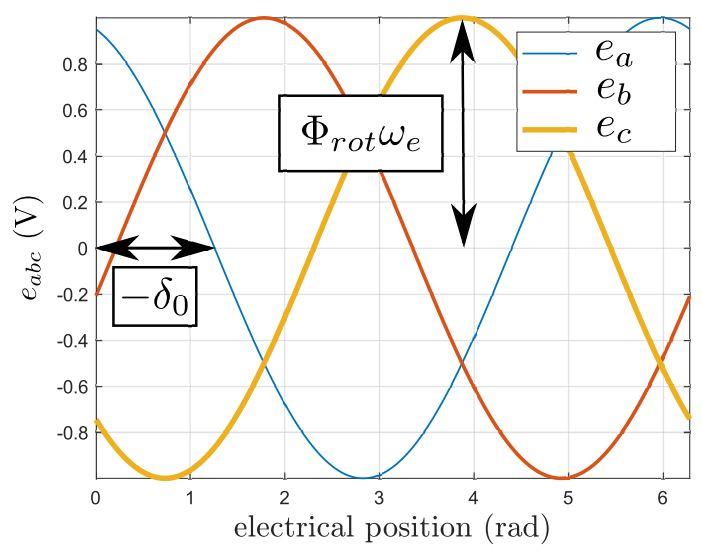

Fig. 2. Normalized back EMF when the rotor is magnetized in the direction $\delta_{0}$ 


\section{B. Considering residual magnetism within the stator}

It should be mentioned that not only the rotor but also the stator is likely to be magnetized. It is important to notice that even if the stator remains static, due to reluctance variations of the SynREL machine (see eq. (2)), a constant magnetization in the stator will produce a flux variation and thus a back EMF. This magnetization must be considered in the proposed residual magnetism model (ReMa Model) for the SynREL machine. Again, a constant magnetization $m_{\text {stat }}$ occurs within the stator in a fixed direction defined by the angle $\sigma_{0}$ (see Fig. 1). Because reluctances are position-dependant in the SynREL motor, the magnetization $m_{\text {stat }}$ produces a flux whose amplitude varies with respect to the motor rotation. This magnetization can be modeled as a positive constant current denoted $I_{\text {stat }}$. The projection into the motor phases leads to $I_{a, \text { stat }}=I_{\text {stat }} \cos \left(\sigma_{0}\right), I_{b, \text { stat }}=I_{\text {stat }} \cos \left(\sigma_{0}-2 \pi / 3\right)$ and $I_{c, \text { stat }}=I_{\text {stat }} \cos \left(\sigma_{0}+2 \pi / 3\right)$.

From Lenz's law ( $\left.e=\frac{d \Phi}{d t}=\frac{d L i}{d t}\right)$ and because $I_{\text {stat }}$ is constant, back EMF are produced according to the following:

$$
\left\{\begin{array}{l}
e_{a, s t a t}=I_{a, s t a t} \frac{d L_{a}}{d t}+I_{b, s t a t} \frac{d M_{a b}}{d t}+I_{c, s t a t} \frac{d M_{c a}}{d t}, \\
e_{b, s t a t}=I_{a, s t a t} \frac{d M_{a b}}{d t}+I_{b, s t a t} \frac{d L_{b}}{d t}+I_{c, s t a t} \frac{d M_{b c}}{d t}, \\
e_{c, s t a t}=I_{a, \text { stat }} \frac{d M_{c a}}{d t}+I_{b, s t a t} \frac{d M_{b c}}{d t}+I_{c, \text { stat }} \frac{\frac{d L_{c}}{d t}}{d t}
\end{array}\right.
$$

It can be demonstrated that these voltages are composed of only one frequency which is twofold the rotational frequency. Using trigonometric relations and assuming $L_{2}=M_{2}$ we get:

$$
\left\{\begin{array}{l}
e_{a, \text { stat }}=-3 I_{\text {stat }} \omega_{e} M_{2} \sin \left(2 \theta_{e}-\sigma_{0}\right), \\
e_{b, \text { stat }}=-3 I_{\text {stat }} \omega_{e} M_{2} \sin \left(2 \theta_{e}-\sigma_{0}-2 \pi / 3\right), \\
e_{c, \text { stat }}=-3 I_{\text {stat }} \omega_{e} M_{2} \sin \left(2 \theta_{e}-\sigma_{0}+2 \pi / 3\right) .
\end{array}\right.
$$

Fig. 3 presents the normalized back EMF produced by residual magnetism within the stator of a SynREL.

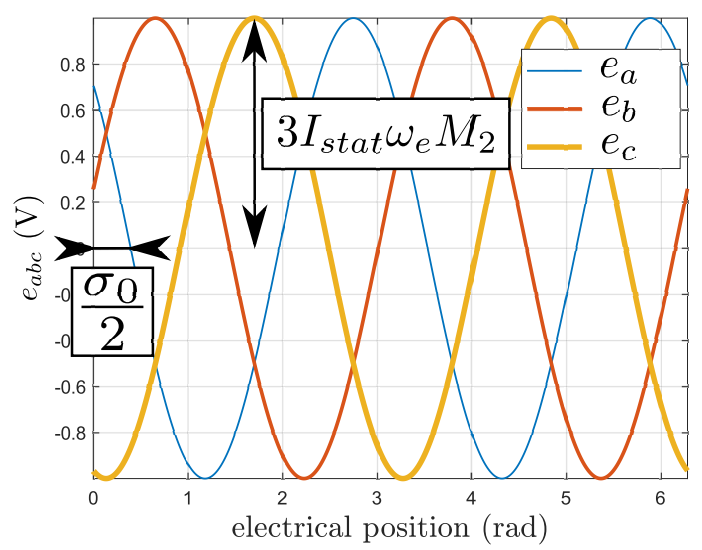

Fig. 3. Normalized back EMF when the stator is magnetized in the direction $\sigma_{0}$

\section{Considering residual magnetism within both the rotor and the stator}

The total back EMF produced when both the stator and the rotor are magnetized is obtained by the addition of (6) and (8). This new model takes into account the residual magnetism in both the rotor and stator, and produces two-frequency back EMF.

$$
\left\{\begin{aligned}
e_{a, t o t}= & -\Phi_{r o t} \omega_{e} \sin \left(\theta_{e}+\delta_{0}\right) \\
& -3 I_{\text {stat }} \omega_{e} M_{2} \sin \left(2 \theta_{e}-\sigma_{0}\right), \\
e_{b, t o t}= & -\Phi_{r o t} \omega_{e} \sin \left(\theta_{e}+\delta_{0}-2 \pi / 3\right) \\
& -3 I_{\text {stat }} \omega_{e} M_{2} \sin \left(2 \theta_{e}-\sigma_{0}-2 \pi / 3\right), \\
e_{c, t o t}= & -\Phi_{r o t} \omega_{e} \sin \left(\theta_{e}+\delta_{0}+2 \pi / 3\right) \\
& -3 I_{\text {stat }} \omega_{e} M_{2} \sin \left(2 \theta_{e}-\sigma_{0}+2 \pi / 3\right) .
\end{aligned}\right.
$$

Fig. 4 presents an example of the simulation results. As can be

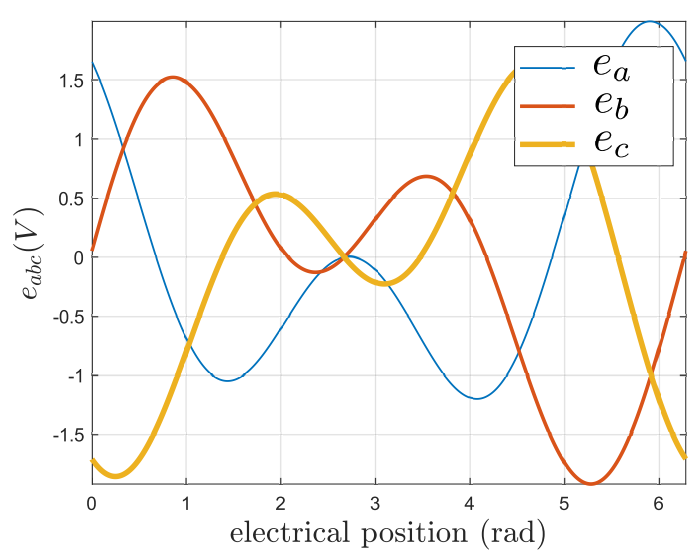

Fig. 4. Simulation of back EMF when both the rotor and stator are magnetized. $\omega_{e}=209 \mathrm{rad} / \mathrm{s}, M_{2}=0.058 \mathrm{H}, \Phi_{\text {rot }}=0.0048 \mathrm{~Wb}$, $I_{\text {stat }}=0.0275 \mathrm{~A}, \sigma_{0}=\pi / 4 \mathrm{rad}, \delta_{0}=-2 \pi / 5 \mathrm{rad}$

seen, a naive measurement of the amplitude by a peak-to-peak measurement is irrelevant for the comparison of produced back EMF. This is especially true since peak-to-peak amplitudes are not identical for each phase. Such a measurement leads to a significant overestimation of the residual magnetism flux within the rotor. A better way to compare back EMF magnitudes is with the Fast Fourier Transform (FFT) amplitude. Considering only total back EMF in phase A, one can notice that the shape is similar to those presented in [22]. It is important to notice that variations in directions $\delta_{0}$ and $\sigma_{0}$ produce significant changes in the shape of the back EMF curve.

Although the sum of all phases of back EMF is zero, the quantity $V_{a}^{2}+V_{b}^{2}+V_{c}^{2}$ is not constant as shown in Fig. 5. This is a divergent point compared to classical three-phase signals produced by only rotor-magnetized models as in (6).

\section{Proposed ReMa model in the Park Reference FRAME}

In the electrical reference frame, the direction of the rotor that involves the maximum of iron is called direction $d$ whereas the so-called $q$ direction is the one with large air-gap (see Fig. 1). With these definitions, the $d$ and $q$ axes are unique and orthogonal in the electrical reference frame. The reference of the electrical position $\theta_{e}$ is chosen such that $\theta_{e}=0 \mathrm{rad}$ coincides with the alignment between the direction $d$ and the phase A windings.

In the rotor reference frame, the Park transform [28] is known to be a truly helpful tool. Hence, resultant equations 


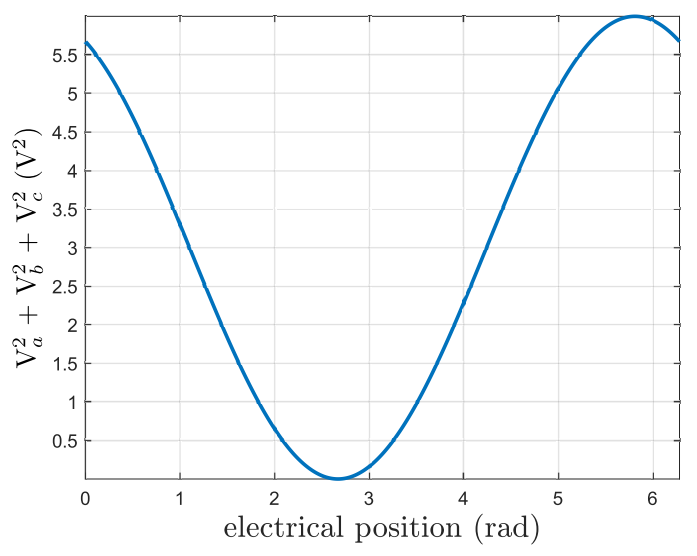

Fig. 5. Simulation of $V_{a}^{2}+V_{b}^{2}+V_{c}^{2}$ when both the rotor and stator are magnetized

are often represented in this frame and electrical machines are generally controlled in it. In this section, we develop the previous ReMa model equations in the Park reference frame. The Concordia-Park transform is chosen as presented in (10). This transform preserves powers but not amplitudes.

$$
P=\sqrt{\frac{2}{3}}\left(\begin{array}{ccc}
\cos \left(\theta_{e}\right) & \cos \left(\theta_{e}-\frac{2 \pi}{3}\right) & \cos \left(\theta_{e}+\frac{2 \pi}{3}\right) \\
-\sin \left(\theta_{e}\right) & -\sin \left(\theta_{e}-\frac{2 \pi}{3}\right) & -\sin \left(\theta_{e}+\frac{2 \pi}{3}\right) \\
\frac{\sqrt{2}}{2} & \frac{\sqrt{2}}{2} & \frac{\sqrt{2}}{2}
\end{array}\right)
$$

With this definition, the inverse transform is carried out by $P^{-1}=P^{\top}$.

$$
\begin{aligned}
& X_{d q 0}=P X_{a b c}, \\
& X_{a b c}=P^{-1} X_{d q 0},
\end{aligned}
$$

where $X$ denotes either currents, voltages or back EMF.

Inductances in the Park reference frame $L_{d}$ and $L_{q}$ can be deduced from $L_{0}, M_{0}$ and $L_{2}, M_{2}$ :

$$
\begin{aligned}
& L_{d}=L_{0}-M_{0}+M_{2}+\frac{1}{2} L_{2}, \\
& L_{q}=L_{0}-M_{0}-M_{2}-\frac{1}{2} L_{2} .
\end{aligned}
$$

If inductance saturations and iron losses are overlooked, the SynREL motor can generally be modeled by (13).

$$
\left\{\begin{array}{l}
L_{d} \frac{d i_{d}}{d t}=v_{d}-R_{s} i_{d}+\omega_{e} L_{q} i_{q}, \\
L_{q} \frac{d i_{q}}{d t}=v_{q}-R_{s} i_{q}-\omega_{e} L_{d} i_{d}
\end{array}\right.
$$

where $i_{d}, i_{q}, v_{d}$ and $v_{q}$ are currents and voltages in the Park rotation frame. Here, just as in section II, no residual magnetism is considered. In this case, the torque produced by the SynREL machines is expressed in (14).

$$
\Gamma_{e m}=n_{p p}\left(L_{d}-L_{q}\right) i_{d} i_{q} .
$$

When a residual magnetism is considered in the machine's rotor as in (6), (15) gives the model of the SynREL machine.

$$
\left\{\begin{array}{l}
L_{d} \frac{d i_{d}}{d t}=v_{d}-R_{s} i_{d}+\omega_{e}\left(L_{q} i_{q}+\sqrt{\frac{3}{2}} \Phi_{r o t} \sin \left(\delta_{0}\right)\right), \\
L_{q} \frac{d i_{q}}{d t}=v_{q}-R_{s} i_{q}-\omega_{e}\left(L_{d} i_{d}+\sqrt{\frac{3}{2}} \Phi_{r o t} \cos \left(\delta_{0}\right)\right) .
\end{array}\right.
$$

If both the residual magnetism within the rotor and the stator are considered (see (9)), the electrical model of the machine becomes:

$$
\left\{\begin{aligned}
L_{d} \frac{d i_{d}}{d t}= & v_{d}-R_{s} i_{d}+\omega_{e}\left(L_{q} i_{q}+\sqrt{\frac{3}{2}} \Phi_{r o t} \sin \left(\delta_{0}\right)\right) \\
& +3 \sqrt{\frac{3}{2}} I_{s t a t} \omega_{e} M_{2} \sin \left(\theta_{e}-\sigma_{0}\right) \\
L_{q} \frac{d i_{q}}{d t}= & v_{q}-R_{s} i_{q}-\omega_{e}\left(L_{d} i_{d}+\sqrt{\frac{3}{2}} \Phi_{r o t} \cos \left(\delta_{0}\right)\right) \\
& -3 \sqrt{\frac{3}{2}} I_{\text {stat }} \omega_{e} M_{2} \cos \left(\theta_{e}-\sigma_{0}\right) .
\end{aligned}\right.
$$

When the residual magnetism within the rotor is taken into account, we need to add a constant term in both equations in (13). This term depends on the direction $\delta_{0}$. Additionally, the residual magnetism within the stator adds positiondependent terms and these terms vary with an angular frequency to the electrical speed. The amplitudes of said terms are identical for both the $d$ and $q$ axis equations.

The model proposed in (16) can be useful for control purposes, especially for applications where residual magnetism has to be considered, such as generator voltage build-up.

\section{EXPERIMENTAL MEASUREMENTS}

\section{A. Description of the test bench}

For the experimental tests, a BSR90LE154055FB5 SynREL machine from Bonfigioli was used as a generator. Its main characteristics are listed in Table I. A Leroy-Somer 95UMC300HAAAA PMSM with the same speed and power range was attached to the SynREL generator by the shafts. This PMSM was connected to a three-phase inverter composed of BSM 50 GB 120 DN2 IGBT. To magnetize the SynREL machine, a three-phase inverter composed of IRF540Z MOSFET was used. Position and speed measurements were provided by an incremental encoder with 5000 points per mechanical revolution. All acquisitions were extracted through a dSpace MicroLabBox Rapid Control Prototyping (RCP) System. The experimental setup is presented in Fig. 6.

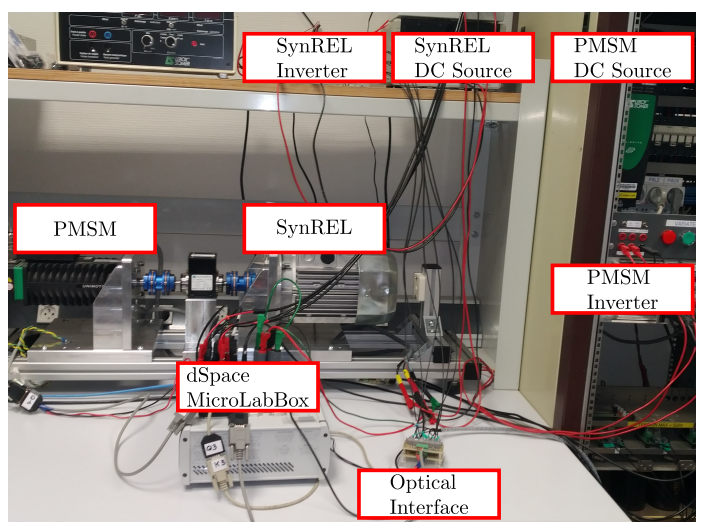

Fig. 6. Experimental setup

\section{B. Magnetization - demagnetization procedure}

The proposed strategy requires a known magnetization ( $\Phi_{\text {rot }}, I_{\text {stat }}$ and directions $\delta_{0}$ and $\sigma_{0}$ ). However, the magnetization depends on previous uses (i.e., the magnetization 
TABLE I

Main Parameters of the Synchronous Reluctance Machine

\begin{tabular}{lll}
\hline \hline Parameters & Value & Units \\
\hline \hline Base speed (mechanical) $\Omega_{m}$ & 1500 & $r p m$ \\
\hline Number of pole pairs $n_{p p}$ & 2 & - \\
\hline Rated current $I_{n}$ & 4.5 & $A$ \\
\hline Power $P_{n}$ & 1500 & $W$ \\
\hline Nominal phase voltage $V_{n}$ & 230 & $V$ \\
\hline Resistance per phase $R_{s}$ & 2.9 & $\Omega$ \\
\hline Unsaturated inductance amplitude $L_{2}$ & 0.078 & $H$ \\
\hline Unsaturated inductance average value $L_{0}$ & 0.144 & $H$ \\
\hline Unsaturated Mutual amplitude $M_{2}$ & 0.058 & $H$ \\
\hline Unsaturated Mutual average value $M_{0}$ & -0.048 & $H$ \\
\hline Unsaturated d-axis inductance $L_{d}$ & 0.289 & $H$ \\
\hline Unsaturated q-axis inductance $L_{q}$ & 0.095 & $H$ \\
\hline
\end{tabular}

history). The machine can be demagnetized by generating a decreasing rotating flux in stand-still conditions. From there, it can be magnetized in a chosen direction $\delta_{0}$ in the rotor reference frame while the rotor position is $\theta_{0}$ as represented in Fig. 1. The fixed direction $\sigma_{0}$ of magnetization in the stator frame can thus be deduced from the rotor position $\theta_{0}$ and the magnetization direction $\delta_{0}$ as (17) during the magnetizing procedure.

$$
\sigma_{0}=\theta_{0}+\delta_{0}
$$

After the demagnetization procedure, by increasing the current, the magnetization follows the initial magnetization curve. Once the desired current $I_{0}$ is reached, we reduce the current down to zero. At this point, the magnetism is non-zero because of the magnetic hysteresis. This process is represented in Fig. 7 for two desired currents $I_{01}$ and $I_{02}$ and this led to two different residual magnetism values $m_{01}$ and $m_{02}$. These residual magnetisms values depended on the non-linear and hysteretic behavior of the ferromagnetic material.

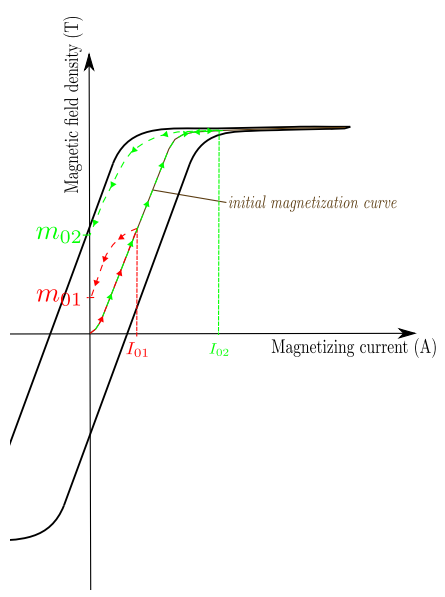

Fig. 7. Schematic of a hysteresis cycle

Fig. 8 shows back EMF measurements achieved on the SynREL machine before (left, magnetizing current $I_{0}=4$ $A \delta_{0}=0 \mathrm{rad} \theta_{0}=6.05 \mathrm{rad}$ ) and after (right) the demagnetization procedure. The vertical scales were identical in order to confirm the effectiveness of the considered demagnetization method.

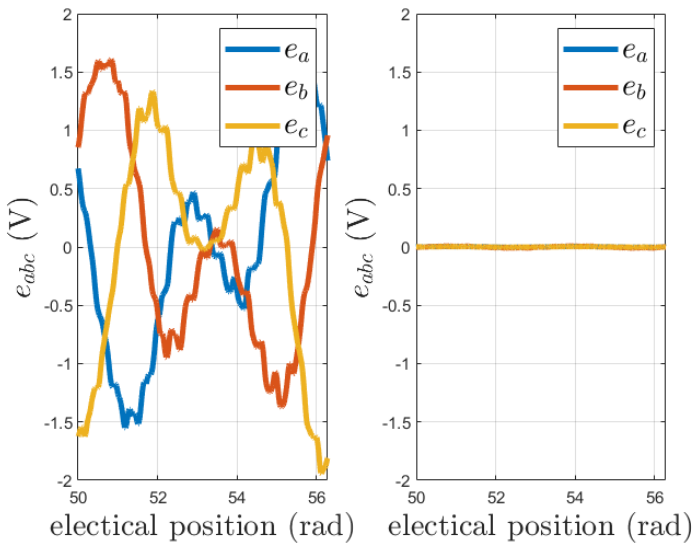

Fig. 8. Back EMF at $\omega_{e}=155 \mathrm{rad} / \mathrm{s}$ before (left, magnetizing current $I_{0}=4 \mathrm{~A}, \delta_{0}=0 \mathrm{rad}, \theta_{0}=6.05 \mathrm{rad}$ ) and after (right) the demagnetization procedure

To validate our model, all measurements were performed according to the following procedure:

- Demagnetization,

- Magnetization in the desired direction and with the desired amplitude,

- Measurement of the quantities of interest.

\section{Validation of the proposed ReMa Model by experimen- tal measurements}

First, an experimental determination of the EMF's amplitude was performed when the SynREL generator was magnetized under different currents. Only small currents $(\leq 50 \%$ nominal value) were considered so as to minimize the impact of inductance saturations. Because of the non-linear phenomena, such as previously mentioned saturations, the back EMF amplitudes were computed from FFT. From these amplitudes, the $I_{\text {stat }}$ and $\Phi_{\text {rot }}$ values could be deduced. A neutral point was available on the tested SynREL machine after which the back EMF values were directly measured between the phases and the neutral point. To simplify data processing and figures, only back EMF in phase A and phase B were measured. $A_{0}$ and $A_{1}$ were considered to be the mean values of amplitudes, normalized with speed, from FFT as expressed in (18).

$$
\begin{aligned}
& A_{0}=\frac{1}{2 \omega_{e}}\left(A_{0, a}+A_{0, b}\right), \\
& A_{1}=\frac{1}{2 \omega_{e}}\left(A_{1, a}+A_{1, b}\right) .
\end{aligned}
$$

Here, $A_{0, a}$ and $A_{0, b}$ are the amplitudes of the fundamental on phase $\mathrm{A}$ and $\mathrm{B}$, respectively, and $A_{1, a}$ and $A_{1, b}$ are the amplitudes of the first harmonic on phase $\mathrm{A}$ and $\mathrm{B}$, respectively.

Fig. 9 exhibits the results for magnetizing currents $I_{0} \in$ $[-2 A ;+2 A]$ in both $d\left(\delta_{0}=0 \mathrm{rad}\right)$ and $q\left(\delta_{0}=\pi / 2\right.$ rad) directions. Because $\sigma_{0}$ has no impact on back EMF amplitudes, it is not specified here. The computed amplitudes $A_{0}$ and $A_{1}$ are also plotted in Fig. 9.

From this figure it can be seen that for the same amount of magnetizing current, the back EMF that were produced when the $d$ axis was magnetized was greater than that produced when the $q$ axis was magnetized. This result was to be 

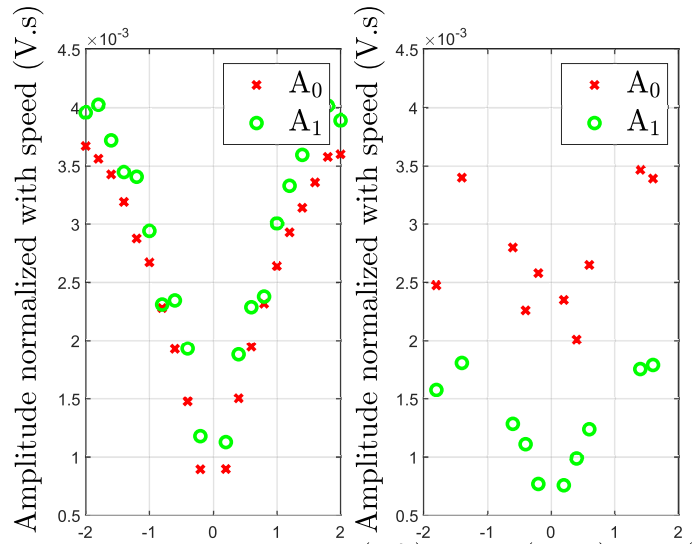

Magnetizing current on $\mathrm{d}$ (left) and $\mathrm{q}$ (right) axis (A)

Fig. 9. Magnitude (normalized with speed) of fundamental and first harmonic when $d$ axis (left) and $q$ axis (right) were magnetized

expected since the $d$ axis presents more iron and is hence more likely to be magnetized. $A_{0}$ and $A_{1}$ depended on the magnetizing current amplitude $I_{0}$ and its direction $\delta_{0}$.

From Fig. 9 the relationship between the amplitude of back EMF and the magnitude of the magnetizing current seemed to be simpler in the direct direction $(d)$ than in the quadrature $(q)$ one. However, determining such a relationship is beyond the scope of this work.

Remark 2. FFT in phase $A$ and $B$ provided very close magnitudes. Especially the amplitudes of the first harmonic were identical for both phases. This justifies the previous hypothesis $M_{2}=L_{2}$ (even though our parameter measurements exhibited different values for $M_{2}$ and $L_{2}$ as listed in Table I).

From the computed amplitudes $A_{0}$ and $A_{1}, I_{\text {stat }}$ and $\Phi_{\text {rot }}$ were deduced based on eq. (6) and (8). Their expressions are given as:

$$
\begin{aligned}
I_{\text {stat }} & =\frac{1}{3 M_{2}} A_{1}, \\
\Phi_{\text {rot }} & =A_{0} .
\end{aligned}
$$

Additionally, with known $\delta_{0}$ and $\theta_{0}$ parameters, the generated back EMF were computed for each phase and were compared to real measurements as shown in Fig. 10. These back EMF values were computed from (9).

The simulated and measured back EMF were very close for a large range of magnetizing currents, even when both $i_{d}$ and $i_{q}$ were used to magnetize the system. Fig. 11 shows the error made between the simulated and measured back EMF for all acquisitions. The quadratic error was computed as the difference between the simulated and measured back EMF raised to squared power, and this was calculated for ten periods. Fig. 11 highlights the measurement corresponding to the one plotted in Fig. 10. It can be seen that this measurement corresponded to a middle one in terms of error. These results validated the new model given in eq. (9).

In order to evaluate our model, phase shifts provided by FFT analysis were compared to those measured during the magnetization procedure. These phase shifts corresponded to the parameters $\delta_{0}$ and $\theta_{0}$ in the proposed model (9). In Fig. 12,

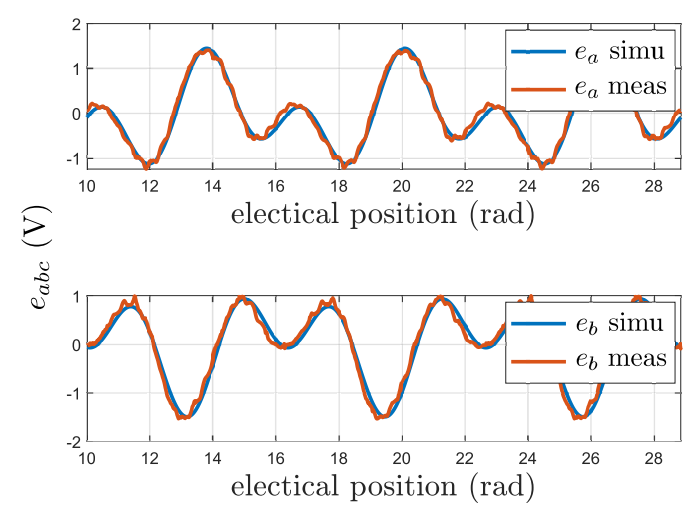

Fig. 10. Comparison between simulated and measured back EMF ( magnetization $I_{0}=1.6 \mathrm{~A}, \delta_{0}=\pi \mathrm{rad}, \theta_{0}=0.75 \mathrm{rad}$ )

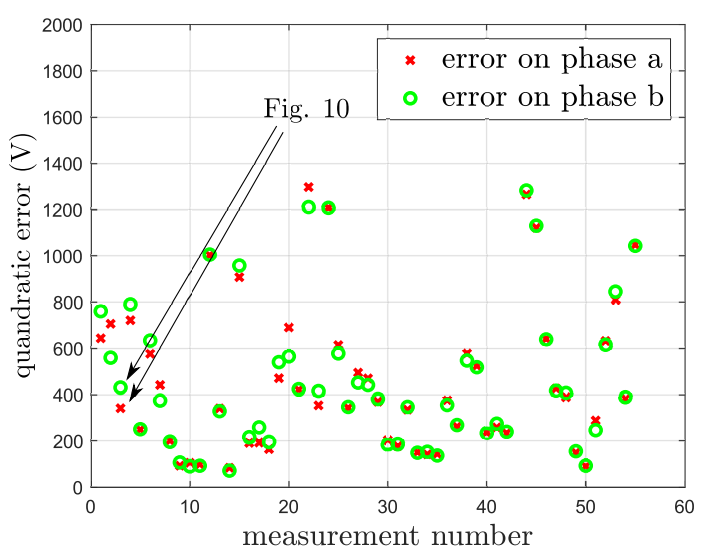

Fig. 11. Error $\sum \sqrt{(e \text { meas }-e \text { simu })^{2}}$ of simulated back EMF

the difference between the measured $\theta_{0}$ and $\delta_{0}$ and those determined by an FFT analysis is plotted. The plotted results show that magnetizing information such as $\delta_{0}$ and $\theta_{0}$ can be deduced from the measurements of back EMF. It validated our new ReMa model given in (9). The last samples (after 44) were obtained from a magnetizing current in both the $d$ and $q$ directions, explaining the slightly larger difference.

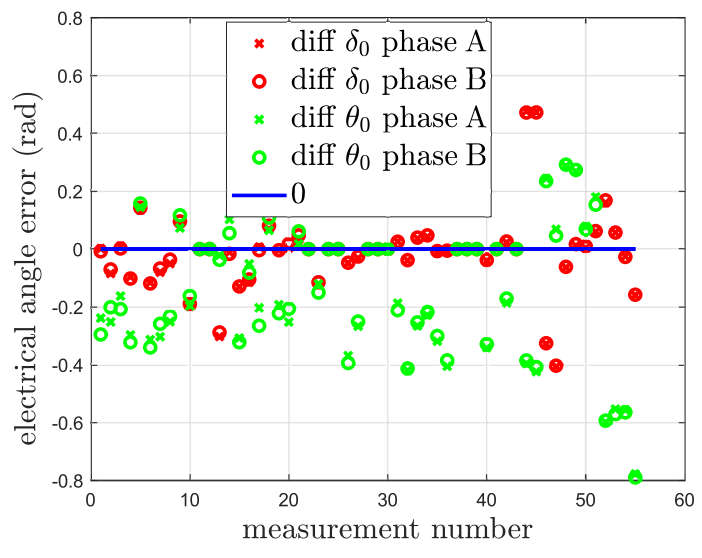

Fig. 12. Difference between phase shifts provided by FFT and the proposed model 


\section{SYNREL GENERATOR CONNECTED TO A THREE-PHASE DIODE RECTIFIER}

Next, the SynREL machine was connected to a three-phase diode rectifier as presented in Fig. 13. In this figure, $i_{d c}$ and $V_{d c}$ are respectively the current and the voltage on the DC side of the rectifier, $i_{\text {cap }}$ denotes the current flowing through the storage capacitor and $i_{L}$ is the current in the resistive load $R_{L}$. The considered system corresponds to a fault operation or a willfully uncontrolled three-phase active rectifier.

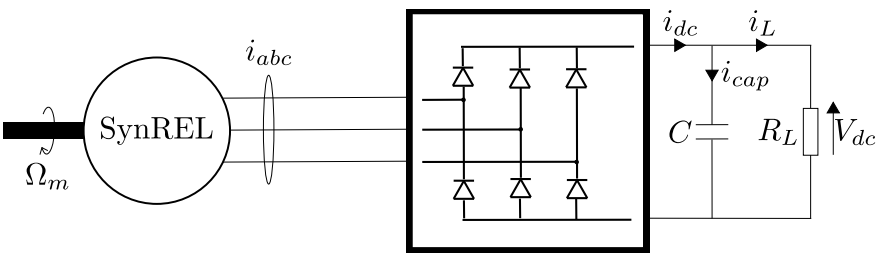

Fig. 13. Diagram of the considered system

Simulations were first performed to compare SynREL and modeled SynREL as PMSM generators connected to a threephase diode rectifier. The latter provides sinusoidal back EMF equivalent to that produced by an only rotor-magnetized back EMF model of a SynREL generator. Subsequently experimental measurements were carried out on the laboratory's SynREL machine.

\section{A. Simulation results}

Since the total power generated by back EMF was not constant (see Fig. 5), the resultant DC voltage differed from the one produced by a sinusoidal back EMF generator connected to the same rectifier. Obviously, the magnitudes were very low. Simulations were performed on a Matlab/Simulink software, and a Simscape library was used. Voltage drops caused by the generator's resistors and inductances were considered using identified machine parameters (see Table I). Because currents were flowing through the rotor windings, there was a risk of demagnetization, as mentioned in [23]. However, considering the extremely small values of generated currents, this threat was not considered in the present work. Fig. 14 exhibits the simulation results that were obtained when the back EMF had the same peak-to-peak amplitudes for both generators.

The only rotor-magnetized generator produced a quasiconstant DC voltage of $0.105 \mathrm{~V}$, while the ReMa-modeled SynREL produced a DC voltage that varied with motor rotational frequency and for which the amplitude was equal to 0.072 $\mathrm{V}$ and the average value was $0.067 \mathrm{~V}$. This discordance was caused by the non-sinusoidal back EMF for the SynREL generator. According to the development proposed in section III, an optimal magnetization direction $\sigma_{0}$ can be considered to maximize the DC voltage produced for the same values of $\Phi_{\text {rot }}$ and $I_{\text {stat }}$. In simulation, the produced DC voltage may be increased by $5 \%$ by choosing the optimum direction of magnetization.

\section{B. Experimental results}

The electrical diagram in Fig. 13 was carried out experimentally with the SynREL machine whose parameters are

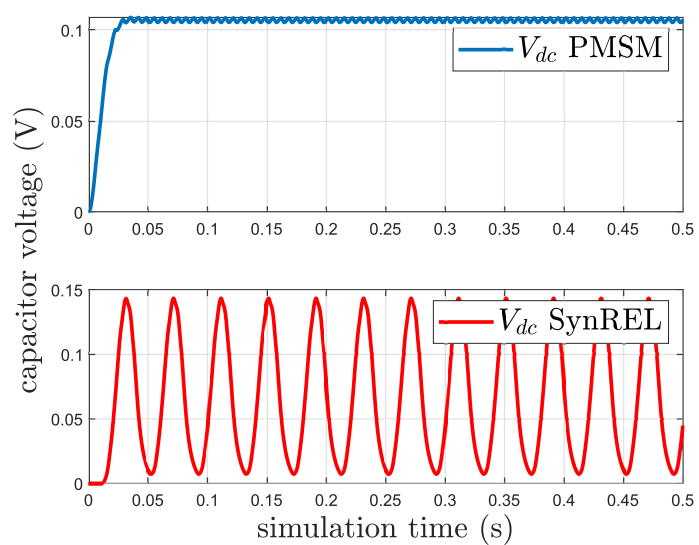

Fig. 14. Comparison between DC voltage produced by only rotormagnetized (down, red) and ReMa-model (up, blue) SynREL generators connected to a three-phase diode rectifier

given in Table I. All the other parameters for this experiment are listed in Table II. The three-phase diode rectifier was made from uncontrolled MOSFET IRF540Z transistors from Infineon. These components have a forward diode voltage of $0.53 \mathrm{~V}$ and a Static Drain-to-Source On-Resistance $R_{\text {on }}$ of $7.8 \Omega$ according to the associated datasheet and considering the small currents involved $(\leq 0.015 \mathrm{~A})$.

TABLE II

Main Parameters of the Synchronous Reluctance Machine

\begin{tabular}{lll}
\hline \hline Parameters & Value & Units \\
\hline \hline Magnetizing current's amplitude $I_{0}$ & 2 & $\mathrm{~A}$ \\
\hline Magnetizing angle $\theta_{0}$ & 2.59 & $\mathrm{rad}$ \\
\hline Magnetizing direction $\delta_{0}$ & 0 & $\mathrm{rad}$ \\
\hline Rotational speed (electric) $\omega_{e}$ & 157 & $\mathrm{rad} / \mathrm{s}$ \\
\hline Storage capacitor $C$ & 0.5 & $\mathrm{mF}$ \\
\hline Load resistor $R_{L}$ & 10 & $\Omega$ \\
\hline
\end{tabular}

The results of this experiment are represented in Fig. 15 plotting a comparison between simulated voltages on phases $\mathrm{A}$ and $\mathrm{B}$ in the two first graphs. The third graph compares the voltage on the capacitor in simulation and in experiment.
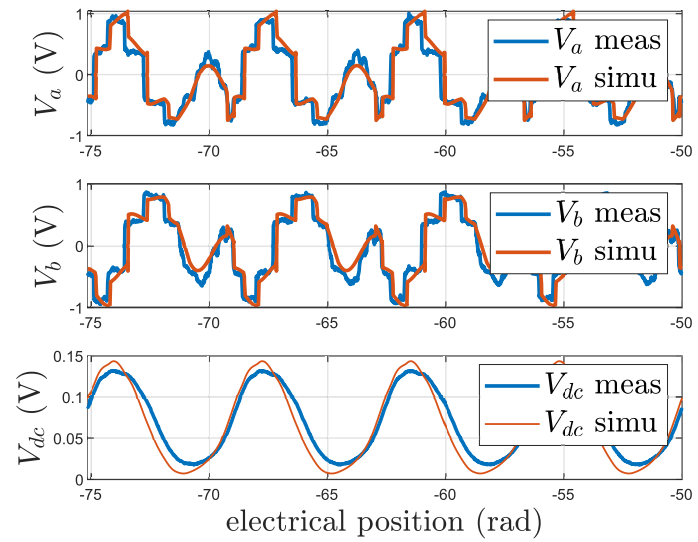

Fig. 15. Comparison between simulations and measurements when the SynREL generator was connected to a three-phase diode rectifier, and the machine was magnetized with $I_{0}=2 \mathrm{~A}, \delta_{0}=0 \mathrm{rad}, \theta_{0}=2.59 \mathrm{rad}$ 
The simulated voltages were close to the measurements. The divergence in measured DC voltage and its simulated counterpart can be explained by the difference between a real threephase diode rectifier and a simulated one in Matlab/Simulink. The large ripple on $V_{d c}$ was caused by non-constant power generated by SynREL back-EMF.

\section{CONCLUSIONS AND FURTHER WORK}

This paper proposes an effective back EMF model (ReMa Model) of a SynREL machine that takes into account residual magnetism in both the rotor and stator. The model requires only few parameters (namely $\delta_{0}, \sigma_{0}, I_{\text {stat }}, \Phi_{\text {rot }}$ ) and produces a two-frequency back EMF in the classical $(a, b, c)$ frame. Comparisons between experimental measurements and simulated back EMF confirmed the accuracy of the proposed model. The advantage of using this ReMa model instead of a classical one involving magnetization in only the rotor was clearly demonstrated in the case study of a generator connected with a rectifier. The proposed ReMa model is also given in the Park reference frame making it usable for control design.

When dealing with SynREL motor applications, back EMF might be considered as perturbations and such perturbations can cause undesirable torque ripples that should be avoided [29] in most of applications. By using the ReMa model, and because back EMF are composed of only two sinusoids, they are likely to be observed in order to be compensated [30]. On the other hand, in case studies of SynREL generators, the ReMa model is helpful when it comes to designing original control laws in order to obtain an effective voltage increase at start-up.

Finally, the method proposed in this paper to obtain a dynamical model including residual magnetism can be extended to other types of electrical machines as IM for example.

\section{REFERENCES}

[1] P. Waide and C. U. Brunner, "Energy-efficiency policy opportunities for electric motor-driven systems," 2011.

[2] N. Bianchi, S. Bolognani, E. Carraro, M. Castiello, and E. Fornasiero, "Electric vehicle traction based on synchronous reluctance motors," IEEE Transactions on Industry Applications, vol. 52, no. 6, pp. 47624769, 2016.

[3] M. A. Rahman, "History of interior permanent magnet motors [history]," IEEE Industry Applications Magazine, vol. 19, no. 1, pp. 10-15, 2012.

[4] I. Boldea, L. N. Tutelea, L. Parsa, and D. Dorrell, "Automotive electric propulsion systems with reduced or no permanent magnets: An overview," IEEE Transactions on Industrial Electronics, vol. 61, no. 10 pp. 5696-5711, 2014.

[5] T. Jahns, "Getting rare-earth magnets out of ev traction machines: A review of the many approaches being pursued to minimize or eliminate rare-earth magnets from future ev drivetrains," IEEE Electrification Magazine, vol. 5, no. 1, pp. 6-18, 2017.

[6] J. Kostko, "Polyphase reaction synchronous motors," Journal of the American Institute of Electrical Engineers, vol. 42, no. 11, pp. 1162 $1168,1923$.

[7] Y. Bao, M. Degano, S. Wang, L. Chuan, H. Zhang, Z. Xu, and C. Gerada, "A novel concept of ribless synchronous reluctance motor for enhanced torque capability," IEEE Transactions on Industrial Electronics, vol. 67, DOI 10.1109/TIE.2019.2914616, no. 4, pp. 2553-2563, 2020.

[8] A. Boglietti and M. Pastorelli, "Induction and synchronous reluctance motors comparison," in 2008 34th Annual Conference of IEEE Industrial Electronics, DOI 10.1109/IECON.2008.4758270, pp. 2041-2044, 2008.

[9] B. Ban, S. Stipetić, and M. Klanac, "Synchronous reluctance machines: Theory, design and the potential u se in traction applications," in 2019 International Conference on Electrical Drives \& Power Electronics (EDPE), pp. 177-188. IEEE, 2019.
[10] H. Kärkkäinen, L. Aarniovuori, M. Niemelä, J. Pyrhönen, and J. Kolehmainen, "Technology comparison of induction motor and synchronous reluctance motor," in IECON 2017-43rd Annual Conference of the IEEE Industrial Electronics Society, pp. 2207-2212. IEEE, 2017.

[11] C. Donaghy-Spargo, "Synchronous reluctance motor technology: opportunities, challenges and future direction." Engineering \& technology reference., pp. 1-15, 2016.

[12] A. Rassolkin, H. Heidari, A. Kallaste, T. Vaimann, J. P. Acedo, and E. Romero-Cadaval, "Efficiency map comparison of induction and synchronous reluctance motors," in 2019 26th International Workshop on Electric Drives: Improvement in Efficiency of Electric Drives (IWED), pp. 1-4. IEEE, 2019.

[13] S. Yamamoto, K. Tomishige, and T. Ara, "A method to calculate transient characteristics of synchronous reluctance motors considering iron loss and cross-magnetic saturation," in Fourtieth IAS Annual Meeting. Conference Record of the 2005 Industry Applications Conference, 2005., vol. 3, pp. 1754-1761. IEEE, 2005.

[14] A. Kilthau and J. Pacas, "Appropriate models for the control of the synchronous reluctance machine," in Conference Record of the 2002 IEEE Industry Applications Conference. 37th IAS Annual Meeting (Cat. No. 02CH37344), vol. 4, pp. 2289-2295. IEEE, 2002.

[15] A. Krings and J. Soulard, "Overview and comparison of iron loss models for electrical machines," Journal of Electrical Engineering, vol. 10, no. 3, pp. 162-169, 2010.

[16] K. Uezato, T. Senjyu, and Y. Tomori, "Modeling and vector control of synchronous reluctance motors including stator iron loss," IEEE Transactions on Industry Applications, vol. 30, no. 4, pp. 971-976, 1994.

[17] Z. Mynar, P. Vaclavek, and P. Blaha, "Synchronous reluctance motor parameter and state estimation using extended kalman filter and current derivative measurement," IEEE Transactions on Industrial Electronics, vol. 68, DOI 10.1109/TIE.2020.2973897, no. 3, pp. 1972-1981, 2021.

[18] J. Elder, J. Boys, and J. Woodward, "The process of self excitation in induction generators," in IEE Proceedings B (Electric Power Applications), vol. 130, no. 2, pp. 103-108. IET, 1983.

[19] R. Bansal, "Three-phase self-excited induction generators: an overview," IEEE transactions on energy conversion, vol. 20, no. 2, pp. 292-299, 2005.

[20] F. Abdel-Kader, "The reluctance machine as a self-excited reluctance generator," Electric machines and power systems, vol. 10, no. 2-3, pp. $141-148,1985$.

[21] A. Mohamadein, Y. Rahim, and A. Al-Khalaf, "Steady-state performance of self-excited reluctance generators," in IEE Proceedings B-Electric Power Applications, vol. 137, no. 5, pp. 293-298. IET, 1990.

[22] Y. Wang and N. Bianchi, "Investigation of self-excited synchronous reluctance generators," IEEE Transactions on Industry Applications, vol. 54, no. 2, pp. 1360-1369, 2017.

[23] M. Ibrahim and P. Pillay, "The loss of self-excitation capability in stand-alone synchronous reluctance generators," IEEE Transactions on Industry Applications, vol. 54, no. 6, pp. 6290-6298, 2018.

[24] S. S. Maroufian and P. Pillay, "Self-excitation criteria of the synchronous reluctance generator in stand-alone mode of operation," IEEE Transactions on Industry Applications, vol. 54, no. 2, pp. 1245-1253, 2017.

[25] S. E. Lyshevski, A. Nazarov, A. El-Antably, A. Sinha, M. Rizkalla, and M. El-Sharkawy, "Synchronous reluctance motors: nonlinear analysis and control," in Proceedings of the 2000 American Control Conference. ACC (IEEE Cat. No. O0CH36334), vol. 2, pp. 1108-1112. IEEE, 2000.

[26] A. Chiba, F. Nakamura, T. Fukao, and M. A. Rahman, "Inductances of cageless reluctance-synchronous machines having nonsinusoidal space distributions," IEEE Transactions on Industry Applications, vol. 27, no. 1, pp. 44-51, 1991.

[27] M.-F. Tsai, C.-S. Tseng, C.-H. Chen, Y.-J. Cheng, and C.-H. Yang, "Phase-variable modeling of a synchronous reluctance motor using psim," in 2016 IEEE 2nd Annual Southern Power Electronics Conference (SPEC), pp. 1-6. IEEE, 2016.

[28] R. H. Park, "Two-reaction theory of synchronous machines generalized method of analysis-part i," Transactions of the American Institute of Electrical Engineers, vol. 48, no. 3, pp. 716-727, 1929.

[29] H. Wu, D. Depernet, V. Lanfranchi, K. E. K. Benkara, and M. A. H. Rasid, "A novel and simple torque ripple minimization method of synchronous reluctance machine based on torque function method," IEEE Transactions on Industrial Electronics, vol. 68, DOI 10.1109/TIE.2019.2962490, no. 1, pp. 92-102, 2021.

[30] W.-H. Chen, J. Yang, L. Guo, and S. Li, "Disturbance-observer-based control and related methods-an overview," IEEE Transactions on Industrial Electronics, vol. 63, no. 2, pp. 1083-1095, 2015. 


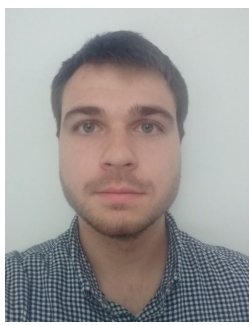

Laurent Schuller received the M.S. degree in electrical engineering from Institut National des Sciences Appliquées de Lyon (INSA Lyon), Villeurbanne, France in 2019 . He is currently pursuing for the Ph.D. degree at the University of Lyon - Institut National des Sciences Appliquées de Lyon (INSA Lyon), Villeurbanne, France. His research interests include electrical motor control and drives.

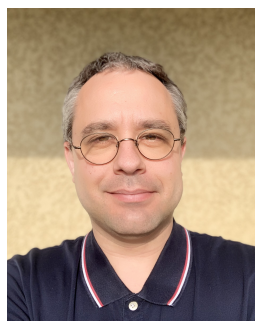

Jean-Yves Gauthier graduated in electrical engineering from Ecole Normale Supérieure, Cachan, France. He received the M.Sc. degree in applied informatics and automation and the Ph.D. degree both from the University of Franche-Comté, France, in 2004 and 2007, respectively. His Ph.D. research fields was about the modeling and the control of magnetic shape memory alloy-based actuators. In 2008, he became an Associate Professor at INSA Lyon, Villeurbanne, France, working at the Laboratoire de Génie Electrique et de Ferroélectricité in semiactive vibration control using piezoelectric devices. Since 2012, he has been working at Ampère Lab, Villeurbanne, France. His current research interests include the control of power electronic devices and electrical motor drives with applications in the fields of transport and energy.

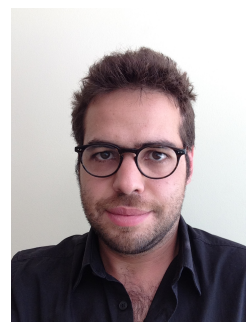

Romain Delpoux received the M.S. degree in control system and mechatronics form the Chalmers University of Technology, Gothenburg, Sweden, in 2009 and the Ph.D. degree in control theory, data and signal processing from the École Centrale de Lille, Villeneuve-d'Ascq, France, in 2012. In September 2014, he joined the Institut National des Sciences Appliquées de Lyon (INSA Lyon), Villeurbanne, France, and the Ampere Laboratory, where he is currently an Associate Professor. His research interests include control applications for power electronics systems, switching systems, and sliding mode control.

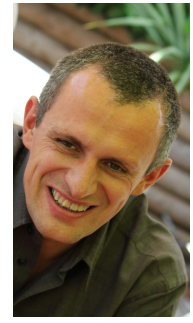

Xavier Brun was born in France in 1973. He received the Ph.D. degree from the Institut $\mathrm{Na}$ tional des Sciences Appliquées de Lyon (INSA Lyon), Villeurbanne, France, in 1999. He became an Associate Professor with the Laboratoire d'Automatique Industrielle, INSA Lyon, in 2001. Since 2011, he has been a Professor at the Laboratoire Ampere, INSA Lyon, France. His current research interests include control for mechatronic and fluid power systems. 